\title{
Finite element analysis of stress extent at peri-implant bone surrounding external hexagon or Morse taper implants
}

\author{
J.P. Macedo $^{\mathrm{a}, *}$, J. Pereira ${ }^{\mathrm{a}, \mathrm{e}}$, J. Faria $^{\mathrm{b}}$, C.A. Pereira, J.L. Alves ${ }^{\mathrm{b}}$, B. Henriques ${ }^{\mathrm{b}, \mathrm{d}, * *,}$, \\ J.C.M. Souza ${ }^{\text {b,d }}$, J. López-López ${ }^{\text {ce,** }}$ \\ a School of Dentistry, Division of Oral Implantology, Universidade Fernando Pessoa (UFP), Porto, Portugal \\ b Center for Microelectromechanical Systems (CMEMS-UMinho), University of Minho, Campus Azurém, 4800-058 Guimarães, Portugal \\ c Oral Health and Masticatory System Group (Bellvitge Biomedical Research Institute) IDIBELL, University of Barcelona, L'Hospitalet de Llobregat, 08907 \\ Barcelona, Spain \\ d Ceramic and Composite Materials Research Group (CERMAT), Federal University of Santa Catarina (UFSC), Campus Trindade, Florianópolis, SC, Brazil \\ e Department of odontostomatology, Faculty of Medicine and Health Sciences (Dentistry), University of Barcelona, Spain
}

\section{A R T I C L E I N F O}

\section{Keywords:}

Bone resorption

Implant design

Marginal bone loss

Morse taper implant

FEA

dental implant

\begin{abstract}
A B S T R A C T
Purpose: The purpose of the present study was to evaluate the distribution of stresses and consequent bone volume affected surrounding external hexagon or Morse taper dental implant systems by finite element analysis. Material and methods: Two different dental implant-abutment designs were assessed: external hexagon or Morse taper joints. A mandibular bone model obtained from a computed tomography scan was used. The implant-abutment systems were axially or obliquely $\left(45^{\circ}\right)$ loaded on $150 \mathrm{~N}$ relatively to the central axis of the implant. The von Mises stresses were analysed in terms of magnitude and volume of affected surrounding bone. Results: The von Mises equivalent values found on the cortical bone were higher than that recorded on the trabecular bone. Additionally, the bone volume associated with high stress values was higher in cortical and trabecular bone for oblique loading compared to axial loading. The values of von Mises equivalent stress around Morse taper implant-abutment system were lower on both axial and oblique loads than those recorded for external hexagon implant-abutment systems.

Conclusions: Morse taper implant joints revealed a proper biomechanical behavior when compared to external hexagon systems concerning a significant volume of surrounding peri-implant bone subjected to lower stresses values.
\end{abstract}

\section{Introduction}

Several mechanical and biological factors can be considered as possible etiological causes for early bone loss surrounding dental implants, such as surgical trauma, occlusal overload, peri-implantitis, presence of microgaps, materials' properties, implant-abutment design (Oh et al., 2002). Mechanical loading associated with the design of implant-abutment or prosthetic geometry plays a major role in longterm success at the moment of initial implant loading (Oshida et al., 2010).Nowadays, attention is given on the maintenance of peri-implant bone and thereby on all requirements for the preservation of periimplant soft tissue in healthy conditions. Several authors state that the most important current issue is to create proper conditions to establish a good boundary between peri-implant tissues and implant-abutment systems in order to guarantee the long-term success of the implant
(Tenenbaum et al., 2003).

During mastication, the occlusal loading is distributed through the prosthetic and implant materials to the peri-implant bone (Siegele and Soltesz, 1989; Macedo et al., 2016; Quirynen et al., 1992; Binon, 2000). High occlusal load affects negatively the distribution of stresses along the structural materials and peri-implant bone (Siegele and Soltesz, 1989; Macedo et al., 2016; Quirynen et al., 1992). Such distribution of stresses depends also on the properties of structural materials and on the dental implant design. Recent developments involve novel morphologic aspects of dental implants and implant-abutment joints such as platform switching associated with Morse taper implant-abutment connection (Siegele and Soltesz, 1989; Macedo et al., 2016). The internal Morse taper implant-abutment design aligns the microgap sizes to be further separated from the marginal bone. The platform switching implant-abutment design has clinically shown to reduce

\footnotetext{
* Corresponding authors.

** Corresponding author at: Center for Microelectromechanical Systems (CMEMS-UMinho), University of Minho, Campus Azurém, 4800-058 Guimarães, Portugal.

E-mail addresses: jmacedo@ufp.edu.pt (J.P. Macedo), brunohenriques@dem.uminho.pt (B. Henriques), 18575jl1@gmail.com (J. López-López).
} 
marginal bone loss and provide additional space for soft tissue development and maintenance over longer follow-up studies (Siegele and Soltesz, 1989; Macedo et al., 2016).

Previous studies have reported the bone loss surrounding different implant-abutment systems by prospective clinical evaluation (Macedo et al., 2016; Clift et al., 1992; Holmes and Loftus, 1997). Also, finite element analysis (FEA) becomes a current method to evaluate the distribution of stresses through different implant-abutment and periimplant bone structures (Siegele and Soltesz, 1989; Clift et al., 1992; Clelland et al., 1993; Zhang and Chen, 1998; Geng et al., 2001; Lotti et al., 2006; Holmgren et al., 1998; Bozkaya et al., 2004; Çehreli et al., 2004; Liang-jian et al., 2011). Finite element analysis of loading transferred to the bone surrounding the implant is an primary step to understand the relationship among peri-implant bone, novel implant design and materials (Zhang and Chen, 1998; Geng et al., 2001; Lotti et al., 2006; Holmgren et al., 1998; Bozkaya et al., 2004; Çehreli et al., 2004; Liang-jian et al., 2011; Bidez and Misch, 1993). Previous FEA studies on osseointegrated implants reported that the maximum stress is located on the cortical bone surrounding the implant (Zhang and Chen, 1998; Holmgren et al., 1998; Bozkaya et al., 2004; Çehreli et al., 2004; Liang-jian et al., 2011). However, most of those studies evaluate the maximum stress value instead of the bone volume on different stress magnitudes.

The aim of this work was to evaluate the volume of peri-implant bone surrounding external hexagon or Morse taper dental implants on different stress magnitudes using the finite element method. The null hypothesis of this study was that there is no difference in bone volume affected by stress distribution around Morse taper or external hexagon dental implant-abutment systems, concerning axial and oblique loading.

\section{Materials and methods}

\subsection{Finite element model design}

Three-dimensional CAD models of Morse taper and external hexagon abutment and implants were supplied by Neodent (C) (Curitiba, Brazil). Then, bi-dimensional images of the implant systems

Rotation axis

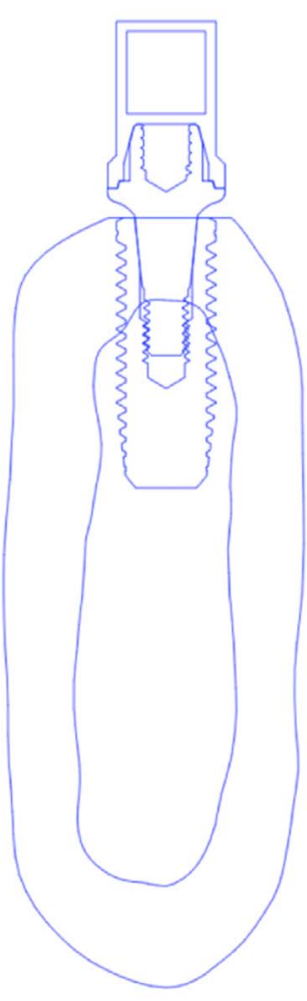

A

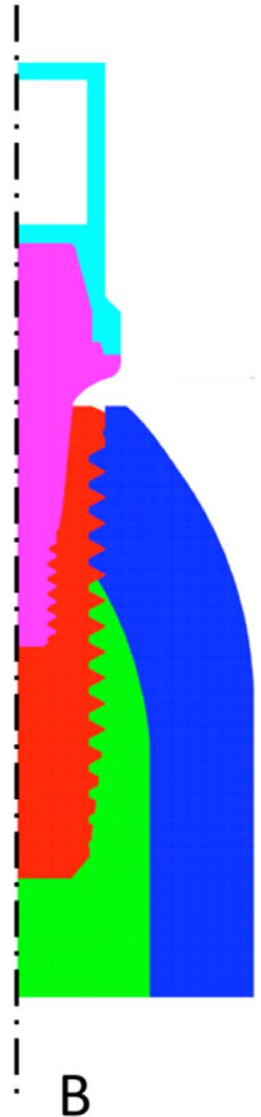

Fig. 2. Dental implant placed in the jaw section obtained by CT scan.

integrated to the bone were built, as shown in Fig. 1. Models of the implant-abutment systems were integrated into a mandible segment in the region of the left premolar teeth in order to perform finite element

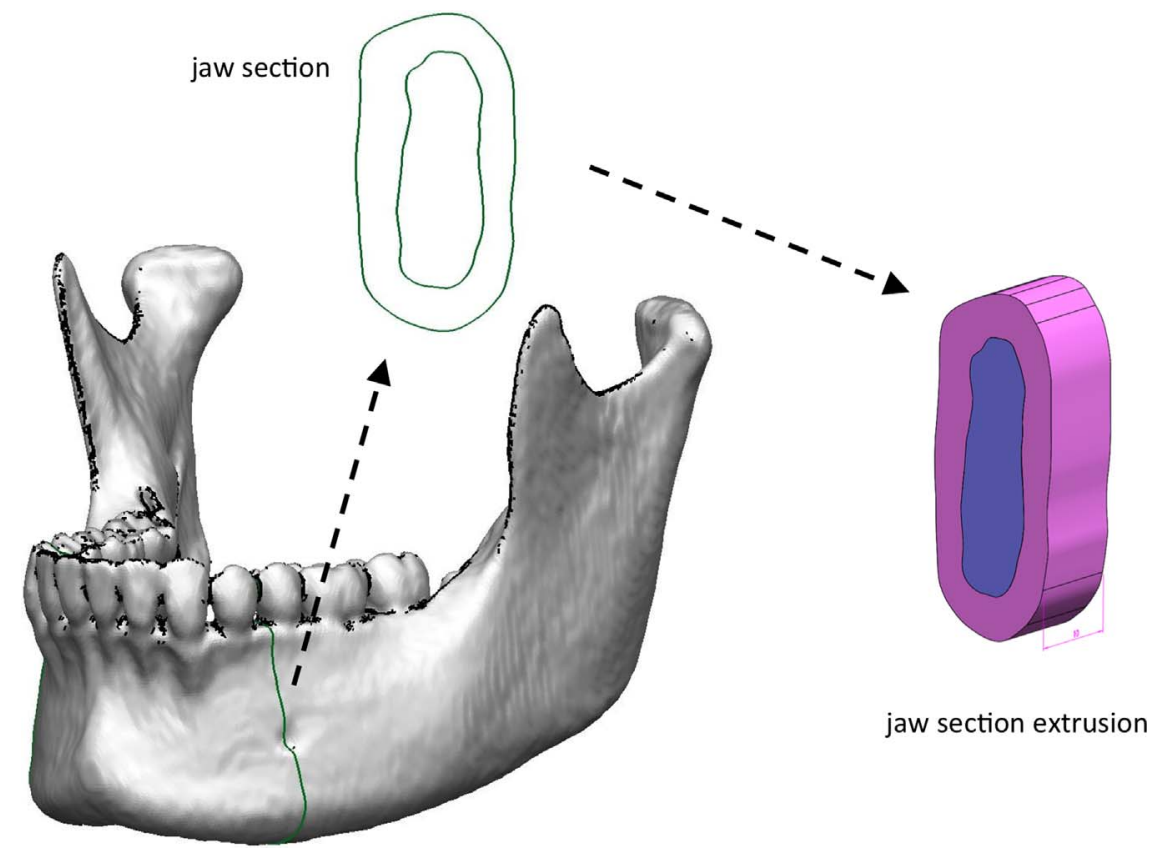

3D model of a CT scan

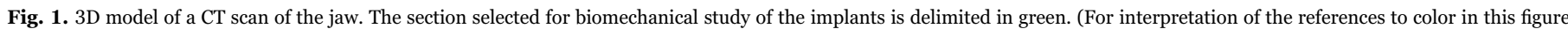
legend, the reader is referred to the web version of this article.) 
analysis (Fig. 1). The model of the mandible (D2 type) (Misch, 1990) was obtained by computerized tomography (CT). A representative section of the mandible with $10 \mathrm{~mm}$ in length, $32 \mathrm{~mm}$ in height and $12.3 \mathrm{~mm}$ width was selected considering a clear division between cortical and trabecular bone. The contours represented in Fig. 1 defined two regions enclosed in a two dimensional plane. The length of the bone segment that consists in the third dimension could be obtained either from the 3D section of the mandible, or else from extrusion of the contours represented in Fig. 1. The morphologic aspects of the cortical and trabecular sections along the entire mandible section were thereby maintained, as shown in Fig. 2.

The cortical bone model was subjected to a process of smoothing and flattening in order to achieve absolute accuracy in the placement of the implants. Thus, the implants were placed exactly at the same distance relatively to the most coronal section of the cortical bone considering surgical recommendations (Bidez and Misch, 1993; Misch, 1990).

\subsection{Finite element analysis}

Deep Drawing 3D implicit Finite Element Code software (DD3imp, Portugal) comprising an enhanced mesh generation algorithm was used for finite element analysis. The contours of the mandible section and the implant were input parameters of the algorithm, as seen in Fig. 3. A different colour was attributed to each independent region of the system to allow a immediate visualization and validation of the system before the mesh generation (Fig. 3). Then, a material was attributed to each colour and a FE mesh was generated representing one fourth of the implant-bone assembly from the simple geometric operations of extrusion and/or revolution of the 2D areas. The cortical bone in dark-blue colours and trabecular bone in green were subjected to an extrusion of $10 \mathrm{~mm}$. Implant structures (red, purple and light-
Table 1

Number of nodes and of tetrahedrons of the mesh structure for external heagon on Morse taper implants. These values reflect only half the problem.

\begin{tabular}{cllll}
\hline & Length & Diameter & $\begin{array}{l}\text { Number of } \\
\text { tetrahedrons }\end{array}$ & $\begin{array}{l}\text { Number of } \\
\text { nodes }\end{array}$ \\
\hline $\begin{array}{c}\text { Morse taper } \\
\text { Titamax }\end{array}$ & 11 & 4 & 816.126 & 154.001 \\
$\begin{array}{c}\text { Cortical } \\
\text { Hexagon } \\
\text { Titamax } \\
\text { Cortical }\end{array}$ & 11 & 4 & 674.442 & 129.021 \\
\hline
\end{tabular}

blue) were submitted to a revolution at $90^{\circ}$ in accordance to the central axis (revolution axis). The thickness of the mandible section $(10 \mathrm{~mm})$ was obtained by the extrusion of the previously identified bone regions. Linear tetrahedrons of about $0.03 \mathrm{~mm}$ side were generated on the threated area of the implant and respective curvature radius to guarantee proper dimensional and geometrical features. The highly refined mesh was then simplified to generate elements of larger or smaller dimensions in an adaptive way at the regions of curvatures that can optimize the dimension and quality of the final finite element mesh. The details of FE mesh (half of the implant) are shown in Fig. 3. The mesh design corresponds to the geometrical features of the interfaces and curvature areas. Since the simulation present boundary conditions, half problem was simulated in order to optimize (minimize) construction time of the model design and FE analysis. The number of nodes and tetrahedrons of each model can be found in Table 1. A convergence analysis was performed in order to examine the sensitivity of the results to the size of the mesh.

The mechanical properties of the structural materials (titanium and bone) were provided for the numerical simulation of the problem
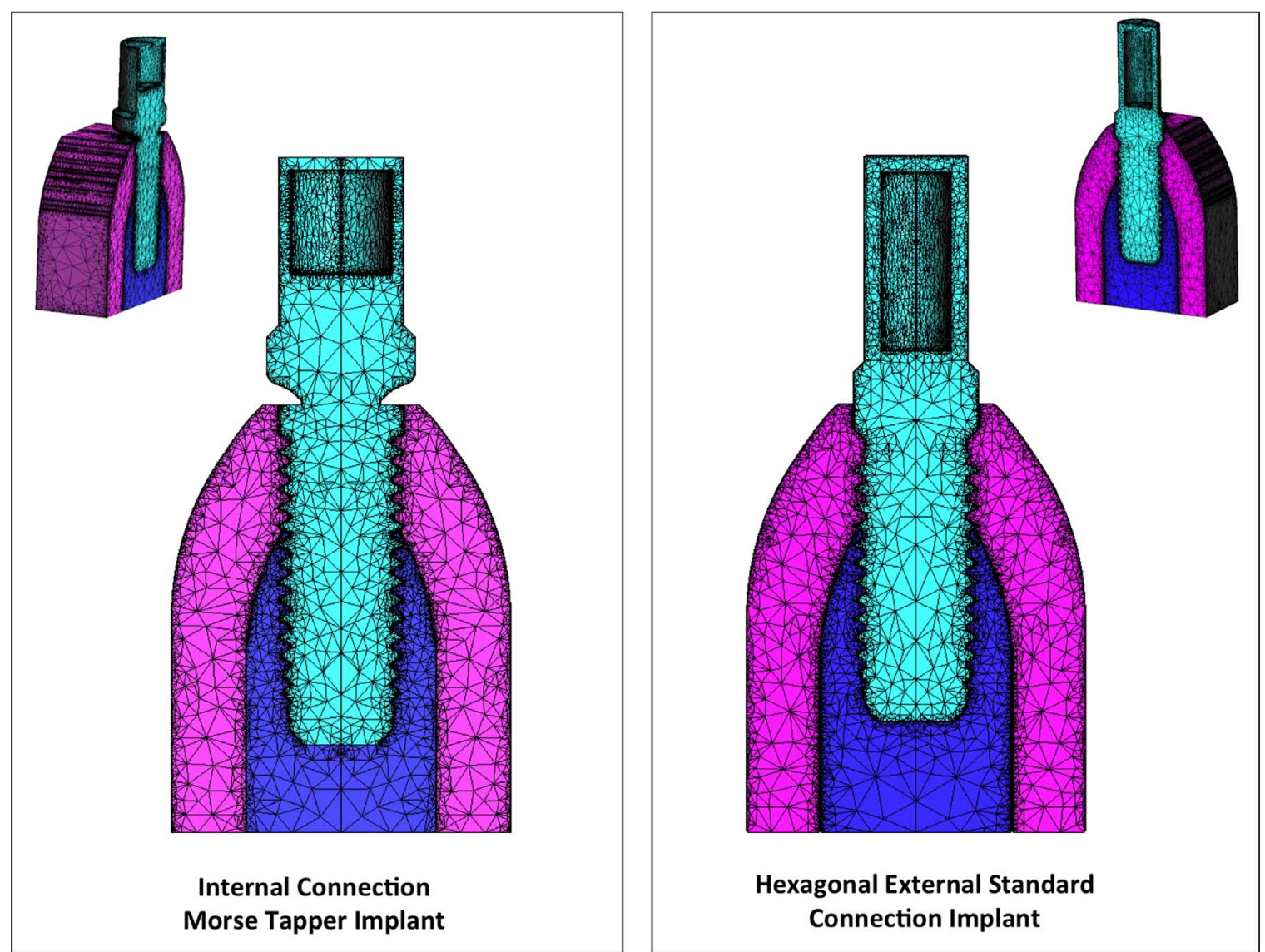

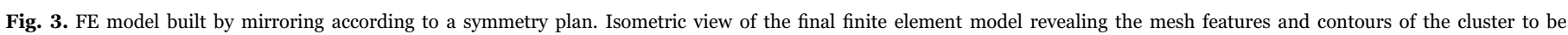
simulated. (For interpretation of the references to color in this figure legend, the reader is referred to the web version of this article.) 
Table 2

Young's Modulus and Poisson's Ratio for the test materials: titanium; trabecular and cortical bone. Adapted from Geng et al. (2001).

\begin{tabular}{llll}
\hline & Trabecular bone & Cortical bone & CP titanium \\
\hline $\begin{array}{c}\text { Young Modulus } \\
\text { [MPa] }\end{array}$ & 500 & 14700 & 110000 \\
Poisson's Ratio & 0.30 & 0.30 & 0.32 \\
\hline
\end{tabular}

according to values found in literature (Zhang and Chen, 1998) (Table 2). Material properties were considered as isotropic and homogeneous.

At the bone-implant interface, a total osseointegration of the implants was considered to occur, therefore a complete bonding between the elements of the bone and implant was modeled. Also, the following boundary conditions and external loads were considered: i) Plane $Z=0$ : The condition of symmetry was ascribed to all nodes at this plane. That can be displaced in $\mathrm{x}$ and $\mathrm{y}$ axes but not in $\mathrm{z}$ axis; ii) Plane $\mathrm{Z}=1$ : opposite to the previous face. All nodes at this face are motionless. That did not allow displacement in $\mathrm{x}, \mathrm{y}$ or $\mathrm{z}$ axis; iii) Plane $\mathrm{Y}=0$ : lower face of the model. All the nodes at this plane are restricted to the direction $\mathrm{x}$ and $\mathrm{y}$. Once the problem was defined, an external load of $150 \mathrm{~N}$ was applied, at the axial or oblique directions. Oblique loading was performed from the buccal side at $45^{\circ}$ relatively to the implant axis.

Due to the numerical nature of this work and due to the fact that additional series of observations would yield the same data, the statistical analysis could not be performed.

\section{Results}

Results of the von Mises stresses (equivalent stress) on both cortical and trabecular bone are shown in Fig. 4. The stress values were discretized according to the volume of bone affected by each nominal stress value (Figs. 5 and 6).

The highest values of von Mises stress were found at the cortical bone surrounding the external hexagon implant joint for both loading conditions, axial and oblique (Fig. 4). The regions of highest stresses were concentrated at the most coronal section of the cortical bone and also at the interface between cortical and trabecular bone (Fig. 4).

On normal load, a higher volume of stressed peri-implant trabecular bone was noticed around Morse taper implant than around external hexagon implant (Fig. 5). Also, the stresses on the trabecular bone were more distributed at Morse taper dental implants. The values of von Mises stress were higher $(0 ; 15 \mathrm{MPa})$ at cortical bone surrounding external hexagon implant (Figs. 4 and 6). The external hexagon implant joint exhibited the highest stresses values (16; Max MPa) of peri-implant bone (Figs. 5 and 6). It can be seen from Fig. 6 that the external hexagon implant joint was associated with higher volume of material on higher stresses, mainly evidenced for stresses above $6 \mathrm{MPa}$.

On oblique loading at $45^{\circ}$, no significant differences were found, as regard to the volume of the affected trabecular bone, between the external hexagon and the Morse taper implant (Fig. 7). Regarding the cortical bone, the bone volume associated with low stresses ( $0 ; 8 \mathrm{MPa})$ was higher around Morse taper implant than around external hexagon

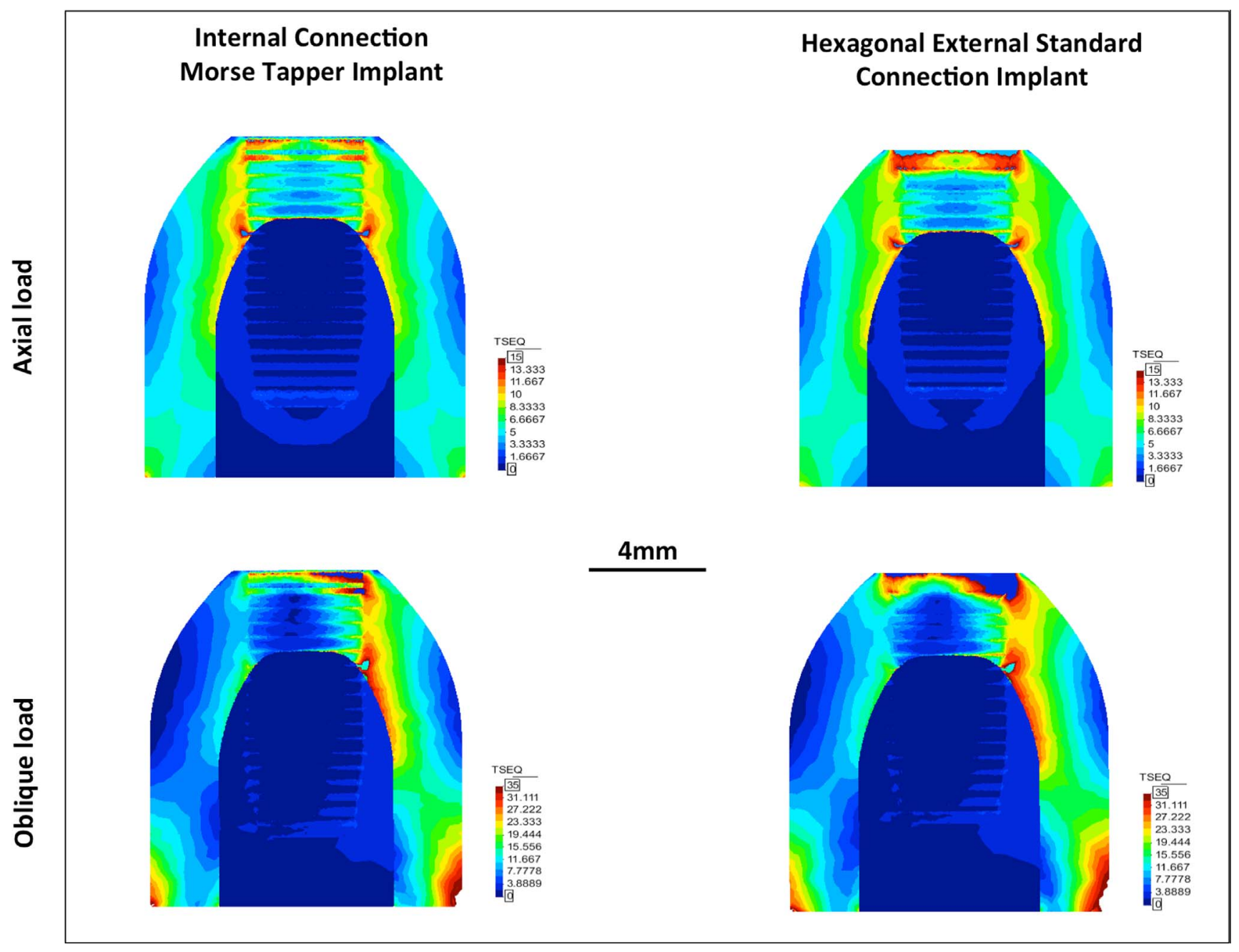

Fig. 4. Distribution of stressses along the test implant-bone area on normal or oblique loading. 
Axial load - Trabecular Bone

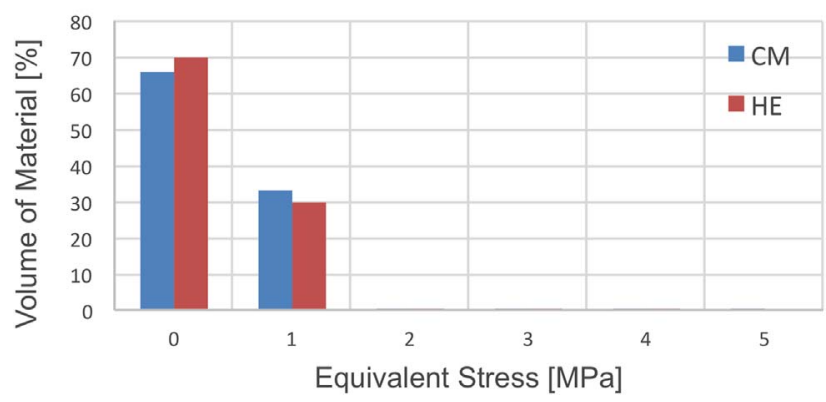

Fig. 5. Volume of trabecular bone related to equivalent stress on normal (axial) loading.

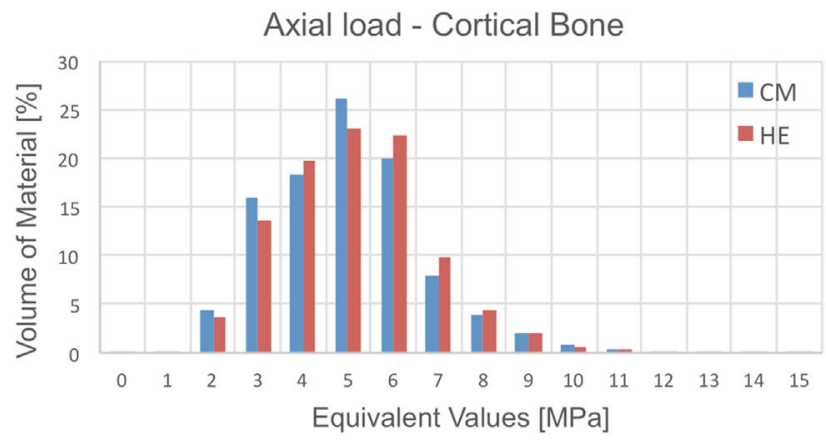

Fig. 6. Volume of cortical bone related to equivalent stress on normal (axial) loading.

Oblique load - Trabecular Bone

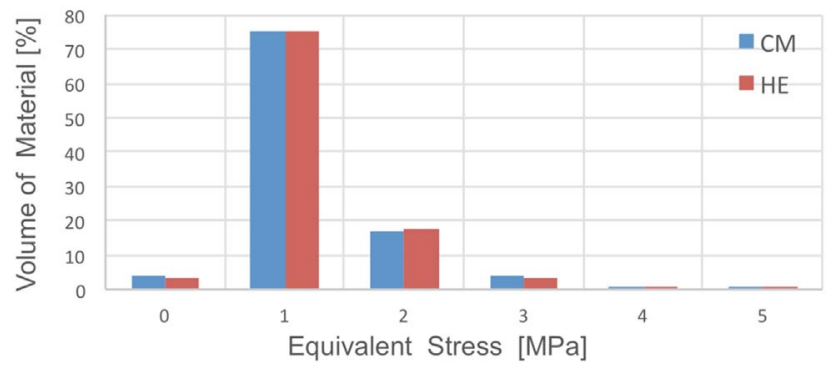

Fig. 7. Volume of trabecular bone related to equivalent stress on $45^{\circ}$ (oblique) loading.

dental implant (Fig. 8). The highest volume of peri-implant bone on stress was recorded for external hexagon implants (36; max MPa) (Figs. 4, 7 and 8). The von Mises stress values on the cortical bone were higher than on the trabecular bone.

\section{Discussion}

The results of the present study support the rejection of the null hypothesis. They showed differences in the stress magnitude and in the volume of affected peri-implant bones between Morse taper and external hexagon implant-abutment systems regarding both normal and oblique loads simulated by finite element method. Such simulation was carried out by static analysis mimicking a slow movement of the jaw during mastication (Wang et al., 2002). Furthermore, all materials were assumed homogeneous, isotropic and linearly elastic, which arises as a limitation of this study. Such simplification results in lower stresses in peri-implant bone ( $20-30 \%)$ in comparison to anisotropic models. However, conclusions drawn from qualitative analyses still valid due to the similarity in stress distributions found in isotropic and anisotropic models. In the present study, the highest values of stress associated with peri-implant bone volume were detected at the cortical bone surrounding the external hexagon implant joint regarding normal and oblique loading. It is important to mention that both cortical and trabecular bone are subjected to stresses. However, the stresses recorded on trabecular bone are at low magnitude, as also corroborated by other previous studies (Bassit et al., 2002; Papavasiliou et al., 1997; Heckmann et al., 2006). The results found in the present study are in accordance with previous studies in literature, as regard to the stress profiles at the peri-implant bones for each loading direction (Holmgren et al., 1998; Papavasiliou et al., 1997; Heckmann et al., 2006). The quality and amount of the surrounding bone influences the load transfer through structural prosthetic and implant materials to the bone (Macedo et al., 2016; Quirynen et al., 1992; Binon, 2000; Clift et al., 1992; Bozkaya et al., 2004; Çehreli et al., 2004; Liang-jian et al., 2011; Wang et al., 2002; Bassit et al., 2002; Papavasiliou et al., 1997; Heckmann et al., 2006). Clift et al. (1992) emphasized the importance of having dense and healthy bone around the implant neck that can withstand stresses ranging from 9 up to $18 \mathrm{MPa}$ prior to loading. Holmes and Loftus (1997) examined the influence of bone quality on the transmission of occlusal forces to endosseous dental implants using FEA. Placement of implants in bone with greater thickness and density of the cortical shell can decrease the micro-movements and stress concentration, thereby increasing the fixture stabilization and tissue integration. As reported in previous studies on FEA, stress field was noticed around the dental implant neck (Bozkaya et al., 2004; Liangjian et al., 2011; Wang et al., 2002; Bassit et al., 2002; Papavasiliou et al., 1997; Heckmann et al., 2006). Clelland et al. (1993) studied the biomechanical behavior of different cancellous and cortical bone models by two-dimensional FEA. On cancellous bone models, low stress and high strain magnitude was noted at the implant apex. For models with a cortical layer, higher crestal stress concentration and lower apical strains were reported. A layer in $3 \mathrm{~mm}$ thickness of isotropic cortical bone generated stresses at least $50 \%$ less than that on a thinner layer at $1.5 \mathrm{~mm}$. Thus, crestal cortical layer thickness and bone isotropy have a substantial impact on resultant stresses and strain

\section{Oblique load - Cortical Bone}

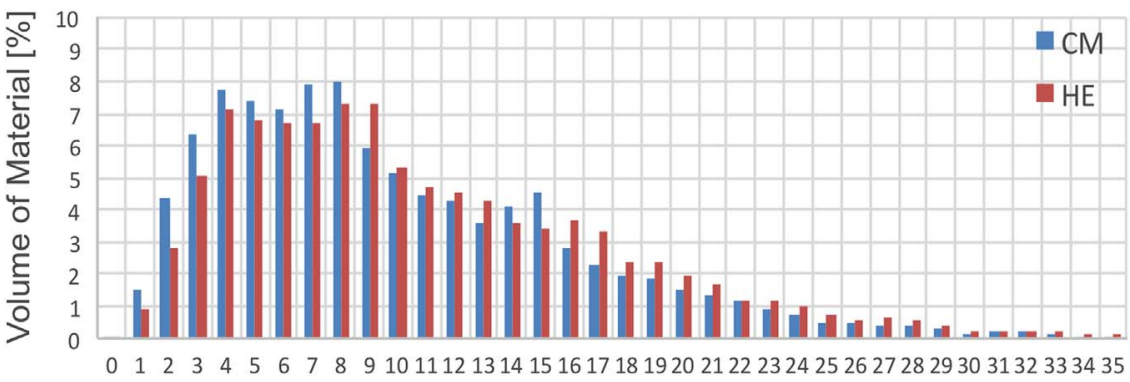

Equivalent Stress [MPa]

Fig. 8. Volume of cortical bone related to equivalent stress on $45^{\circ}$ (oblique) loading. 
magnitude.

Also, it is important to consider oblique loading instead of only normal loading, which can combine the resultant forces from normal and horizontal loading. Oblique forces are often acting on implantsupported prostheses and bone during mastication resulting in periimplant stresses that depends on several factors related to materials, design and bone structure (Holmgren et al., 1998). The oblique loading generates stresses on the opposite peri-implant bone area at higher magnitude than those found on normal loading both in cortical and trabecular bone. That results in higher cortical bone extent affected by stresses when compared to the cortical bone on normal loading (Rangert et al., 1989). Consequently, the elastic limit of bone surrounding implants can be overcome, which might lead to microscale cracks in the cortical bone. Previous studies reported that the highest bone remodeling events coincide with the regions of highest equivalent stress. Also, the major remodeling differences between axial and non-axial loading are largely determined by the horizontal stress directions (Clelland et al., 1993; Zhang and Chen, 1998; Geng et al., 2001; Heckmann et al., 2006). The importance of avoiding or reducing horizontal loading should be emphasized. Other previous studies includes oblique forces to simulate the static or dynamic loading during mastication or occlusal contact (Geng et al., 2001; Lotti et al., 2006; Holmgren et al., 1998; Papavasiliou et al., 1997; Heckmann et al., 2006). For instance, Zhang and Chen (1998) compared threedimensional FEA models at dynamic or static loading on dental implants having varied the elastic moduli values. Their study showed that the dynamic load model resulted in higher maximum stress at the bone-implant interface when compared to the static load models.

Considering the difficulty in performing in vivo studies, the numerical analysis of stresses acting at peri-implant bone by the finite element technique has taken a major role in the study of the relationship between implant and bone. Thus, the advantages and disadvantages of both strategies should be listed. Finite element analysis provides the possibility to predict the stress distribution at implant and cortical bone regions as well as at the most apical area of the implant and the trabecular bone. In fact, such technique can predict the biomechanical performance of different implant concerning design, loading, bone quality and materials (Zhang and Chen, 1998; Geng et al., 2001). On the other hand, there are limitations in FEA that must be considered and that can derive from mesh generation and boneimplant interface (Zhang and Chen, 1998; Geng et al., 2001; Lotti et al., 2006). In the present study, it was allowed to evaluate in details the stress magnitude and bone volume extent of peri-implant bone around two different implant designs, namely Morse taper and external hexagon dental implants. The present study isolated the biomechanical evaluation from other side effects, such as any potential specificities of individual variation in mandible section near the region of the implant placement. Variables that could occur in a real bone segment obtained by CT, such as dimensions and quality of cortical and marrow bone as well as skeletal variations caused by the region's anatomy were therefore excluded. Also, the software used in the present study provided a mesh generation with higher geometrical resolution when compared to other ones reported in literature.

The clinical success of a dental implant requires not only osseointegration, but also the development of a biological sealing; i.e., a soft tissue seal around the trans-mucosal region of the implant. The implant-abutment connection is a critical region to establish the biological seal of dental implants (Oh et al., 2002; Oshida et al., 2010; Tenenbaum et al., 2003; Siegele and Soltesz, 1989; Macedo et al., 2016; Quirynen et al., 1992). The presence of micro-gaps can induce the accumulation of oral biofilms including pathogenic species. That can stimulate inflammatory reactions and consequent crestal bone loss (Oh et al., 2002; Macedo et al., 2016). The use of Morse taper connection implants associated with platform switching represents a successful approach to decrease bone loss. Also, the mechanical stability and design of implant-abutment connections results in a proper stress distribution from occlusal loads to the bone. Nevertheless, there is lack of clinical evidences regarding the threshold of stress magnitude related to bone remodeling. The biomechanical behavior revealed by Morse taper implants is linked to a harmony among bone, soft tissues and implant. Consequently, that leads to physiologic blood supply and cellular behavior avoiding stimulation of inflammatory reactions at peri-implant region.

It is important to highlight at this stage that despite several studies are available in literature on the biomechanical behavior of different implant systems, the majority focused on the maximum stresses and strains undergone by the implant system or bones. To the best knowledge of the authors, this study is a first attempt to quantify in detail the amount of peri-implant bone (given in percentage of volume) subjected to the different levels of stress. Nevertheless, the results of this study are in agreement with the results reported in literature concerning the maximum stresses and stress distribution on Morse taper and external hexagon implant-abutment systems.

\section{Conclusion}

Within the limitations of finite element analysis performed in this study, it was possible to evaluate in detail the stress magnitude and volume affected around peri-implant bone for two different implant designs, namely Morse taper and external hexagon dental implants. The von Mises stresses on the cortical bone were higher than those recorded on the trabecular bone, for axial or oblique loading. Additionally, Morse taper implants exhibited higher volume of periimplant bone on low stresses and lower volume of peri-implant bones at high stresses. Thus, Morse taper implant systems revealed better biomechanical behavior when compared to external hexagon implants, concerning significant bone volume subjected to low stress magnitude.

\section{Acknowledgments}

The authors acknowledge the support provided by the Dept. of Mechanical Engineering at the University of Minho (Portugal) and by Drawing 3D implicit Finite Element Code (DD3imp, Portugal). This study was supported by FCT-Portugal (EXCL/EMS-TEC/0460/2012; UID/EEA/04436/2013, NORTE-01-0145-FEDER-000018 HAMaBICo), CNPq-Brazil (PVE/CAPES/CNPq/407035/2013-3).

\section{References}

Bassit, R., Lindström, H., Rangert, B., 2002. In vivo registration of force development with ceramic and acrylic resin oclusal materials on implant-supported prostheses. Int. J. Oral Maxillofac. Implants 17, 17-23.

Bidez, M.W., Misch, C.E., 1993. Clinical biomechanics. In: Misch, C.E. (Ed.), Contemporary Implant Dentistry 15. Mosby, St Louis, 279B-311B.

Binon, P.P., 2000. Implants and components: entering the new millennium. Int. J. Oral Maxiloffac. Implants 15, 76-94.

Bozkaya, D., Muftu, S., Muftu, A., 2004. Evaluation of load transfer characteristics of five different implants in compact bone at different load levels by finite elements analysis. J. Prosthet. Dent. 92, 523-530.

Çehreli, M.C., Akça, K., Iplikçio!glu, H., 2004. Force transmission of one- and two-piece Morse-taper oral implants: a nonlinear finite element analysis. Clin. Oral Implants Res. 15, 481-489.

Clelland, N.L., Lee, J.K., Bimbenet, O.C., Gilat, A., 1993. Use of an axisymmetric finite element method to compare maxillary bone variables for a loaded implant. J. Prosthodont. 2 (3), 183-189.

Clift, S.E., Fisher, J., Watson, C.J., 1992. Finite element stress and strain analysis of the bone surrounding a dental implant: effect of variations in bone modulus. Proc. Inst. Mech. Eng. H 206 (4), 233-241.

Geng, J.P., Tan, K.B., Liu, G.R., 2001. Application of finite element analysis in implant dentistry: a review of the literature. J. Prosthet. Dent. 85, 585-598.

Heckmann, S.M., Karl, M., Wichmann, M.G., Winter, W., Graef, F., Taylor, T.D., 2006 Loading of bone surrounding implants through three-unit fixed partial denture fixation: a finite-element analysis based on in vitro and in vivo strain measurements. Clin. Oral Impl. Res. 17, 345-350.

Holmes, D.C., Loftus, J.T., 1997. Influence of bone quality on stress distribution for endosseous implants. J. Oral Implantol. 23 (3), 104-111.

Holmgren, E.P., Seckinger, R.J., Kilgren, L.M., Mante, F., 1998. Evaluating parameters of osseointegrated dental implants using finite element analysis: a two-dimensional 
comparative study examining the effects of implant diameter, implant shape, and load direction. J. Oral Implantol. 24, 80-88.

Liang-jian, C., Hao, H., Yi-min, L., Ting, L., Xiao-ping, G., Rui-fang, W., 2011. Finite element analysis of stress at implant-bone interface of dental implants with different structures. Tans. Nonferrous Met. Soc. China 21, 1602-1610.

Lotti, R.S., Machado, A.W., Mazzieiro, E.T., Landre Júnior, J., 2006. Aplicabilidade científica do método dos elementos finitos. R. Dental Press Ortodon. Ortop. Facial $11,35-43$.

Macedo, J.P., Pereira, J., Vahey, B.R., Henriques, B., Benfatti, C.A.M., Magini, R.S., López-López, J., Souza, J.C.M., 2016. Morse taper dental implants and platform switching: The new paradigm in oral implantology. Eur. J. Dent. 10 (1), 148-154.

Misch, C.E., 1990. Density of bone: effect on treatment plans, surgical approach, healing, and progressive bone loading. Int. J. Oral Implantol. 6 (2), 23-31.

Oh, T.J., Yoon, J., Misch, C.E., Wang, H.L., 2002. The causes of early implant bone loss: myth or since? J. Periodontol. 73, 322-333.

Oshida, Y., Tuna, E.B., Aktören, O., Gençay, K., 2010. Dental implant systems. Int. J. Mol. Sci. 11, 1580-1678.

Papavasiliou, G., Kamposiora, P., Bayne, S.C., Felton, D.A., 1997. 3D FEA of osseointegration percentages and patterns on implant-bone interfacial stresses. J. Dent. 25, 485-491.

Quirynen, M., Naert, I., van Steenberghe, D., 1992. Fixture design and overload influence marginal bone loss and future success in the Brånemark system. Clin. Oral Implants Res. 3, 104-111.

Rangert, B., Jemt, T., Jörneus, L., 1989. Forces and moments on Branemark implants. Int. J. Oral Maxillofac. Implants 4, 241-247.

Siegele, D., Soltesz, U., 1989. Numerical investigations of the influence of implant shape on stress distribution in the jaw bone. Int. J. Oral Maxillofac. Implants 4, 333-340.

Tenenbaum, H., Schaaf, J.F., Cuisinier, F.J., 2003. Histological analisys of the Ankylos peri-implant soft tissues in a dog model. Implant Dent. 12, 259-265.

Wang, T.M., Leu, L.J., Wang, J., Lin, L.D., 2002. Effects of prosthesis materials and prosthesis splinting on peri-implant bone stress around implants in poor-quality bone: a numeric analysis. Int. J. Oral Maxillofac. Implants 17, 231-237.

Zhang, J.K., Chen, Z.Q., 1998. The study of effects of changes of the elastic modulus of the materials substitute to human hard tissues on the mechanical state in the implant-bone interface by three-dimensional anisotropic finite element analysis. West China J. Stomatol. 16, 274-278. 